\title{
Are We There Yet? A Probing Study to Inform Design for the Rear Seat of Family Cars
}

\author{
David Wilfinger, Alexander Meschtscherjakov, Martin Murer, \\ Sebastian Osswald, and Manfred Tscheligi \\ Christian Doppler Laboratory "Contextual Interfaces", ICT\&S Center, University of Salzburg, \\ Sigmund Haffner Gasse 18, 5020 Salzburg, Austria \\ \{david.wilfinger, alexander.meschtscherjakov, martin.murer, \\ sebastian.osswald, manfred.tscheligi\}@sbg.ac.at
}

\begin{abstract}
When researching interactive systems in the car, the design space can be divided into the following areas: driver, front seat passenger and rear seat. The latter has so far not been sufficiently addressed in HCI research, which results in an absence of implications for interaction designs in that space. This work presents a cultural probing study investigating the activities and the technology usage in the rear seat as social and physical space. The study was conducted with 20 families over a period of four weeks and unveiled aspects relevant for HCI research: aspects of diversion, educational motivation, togetherness, food as activity, physical space, perception of safety, and mobile computing. In relation to these areas, implications for the design and integration of interactive technology in the rear seat area are deduced. We show that cultural probing in the car is a promising and fruitful approach to get insights on passenger behavior and requirements for interactive systems. To improve the rear seat area and to show the potential of probing results to inform design, a design proposal for an interactive rear seat game called RiddleRide is introduced.
\end{abstract}

Keywords: rear seat, design space, cultural probing, car, design.

\section{Introduction}

User Interfaces in cars have gained growing attention in HCI research (e.g. [15]). With an increasing amount of interactive technology being introduced to cars, HCI has developed valuable approaches to improve users' experience in the vehicle. Nevertheless most interfaces designed and studies conducted focus on the driver and the surrounding space (e.g. [8], [16]). Additionally, recent work also focuses on the front seat passenger (e.g. collaboration [6]). Within the car an additional third area - the rear seat - can be identified. Investigating not only the driver and front seat passenger, but targeting the rear seat passengers as well would extend traditional interactive systems into multi-party systems that provide role-based access to available devices and services [13].

We suggest dividing the design space in the vehicle into three main areas, namely the driver's area, the front passenger's area and the rear seat area. In order to create a 
holistic image of the car as usage context of technology either novel methods to investigate this special area need to be contrived, or already existing methods need to be adapted. This work will introduce cultural probing [7] as an adapted method to research "rear seat" in terms of physical and social space.

\subsection{Motivation}

Although modern cars are manufactured highly standardized, the industry has provided its customers a multitude of different personalization possibilities. Most of those are related either to the whole car (e.g. motorization, color) or to the drivers and their needs (e.g. navigation systems, steering wheel remote controls). Despite novel approaches like rear seat entertainment systems, the rear seat area is the area with the lowest personalization possibilities when buying a vehicle. Therefore it is necessary to investigate adaptations users make in their rear seat areas and ideas they have to redesign this space. The usefulness of researching self-done adaptations and artifacts was already acknowledged within the HCI community, where do-it-yourself (DIY) HCI has gained recent attention [5].

Additionally, passengers in the rear seat do not have to conduct driving relevant tasks. This often leads to boredom and an extended wish for entertainment. Interactive systems, which are already common in other usage contexts (e.g. homes, airplanes) like video and computer games have been increasingly situated in the modern cars. Since these contexts differ from each other, user requirements for entertainment in cars are a significant area for research.

Children, who are often passengers in the rear seat area, are an important user group in the car. Following the statistics provided by the NHTS (National Household Travel Survey) children in the US between the ages of 5-15 years travel on average 39,29 minutes per day in a private owned vehicle [14]. Their wellbeing has a major impact on the atmosphere in the vehicle. This can range from a positive effect on the driver when the kids are happy, to a real safety threat when drivers cannot focus on their driving tasks anymore. Therefore, the front seat passengers are highly relevant sources of information when designing for the rear seat area since they are directly affected by what happens behind them.

Automotive HCI research so far has been focused mainly on the driver and the cockpit whilst neglecting the rear seat. Nevertheless, the relevance of this space was already identified by researchers and designers [11]. One of the few studies targeting the rear seat has been presented by [13] introducing a system that supports the communication between passengers in the vehicle.

\subsection{Research Goals}

The above-mentioned reasons led us to the conviction that the investigation of the rear seat area is highly relevant for the HCI community. As a first step to approach the rear seat as interaction space, we therefore aimed at investigating the usage of the rear seat by families, with mainly kids traveling in the rear seats. We acknowledge that the usage of the rear seat area is more diverse with other passengers than children, but view this study as a start for further investigations in that space. In the presented study, the following research goal is investigated: 
- How is the rear seat area used by families and which implications for HCI exist when introducing technology in this area of the car?

In more detail the following sub goals are identified:

- Which weaknesses of the rear seat area exist and how are they fixed by families?

- Which activities are conducted in family cars in the rear seat area?

- Which artifacts are used by families for their rear seat activities?

- What are participating families requirements for a "perfect" rear seat area including interactive technology?

- How is technology used in the rear seat area of family cars and what are implications for the design of future interactive technology?

\subsection{Method}

To investigate the research goals, we chose the cultural probing method, originally developed by [7]. Probing studies contain packages that include open-ended, provocative and oblique tasks that support an engagement of participants early in the design process. The main idea is to involve participants, encourage them to take photos, write diaries, send postcards and conduct other kinds of activities that facilitate a creative approach to the study topic. The underlying idea is to get unknown ideas from a group the researchers are not familiar with.

Meanwhile, different variations of the cultural probing method have been presented (e.g., organizational probes [17] and perspective probes [2]). Probing studies were additionally conducted in different contexts researching technology usage, such as the home [3]. Recent research within the HCI community has utilized cultural probes in order to study life-logging practices [15], or to investigate emotions experienced by families living geographically distant [10].

Why Probing? Probing studies and their results are often criticized due to the nature of the probing results. Probes give insights on users in a very subjective way and their interpretation is of a very subjective nature too. Bill Gaver (as cited in [4]), however states that the uncertainty of probes is an asset. Probing additionally enables researchers and designers to understand everyday life situations and allows them to get a sense of context and how participants live in it [11]. Another advantage of applying cultural probing in family cars is the absence of a researcher. Common car usage is likely to be influenced by the presence of a researcher, as the car is a very private setting with a limited amount of space. Another strength of the probing approach is the possibility to gather information over a longer period of time, leading to insights different to short time qualitative methods like interviews.

Probing as a method enables the researcher to gain insights into those complex and emotionally laden processes that have evolved within the rear seat area and in the interaction between front and back row. This gives probing an advantage compared to other in-situ methods like contextual inquiry or ethnographic methods. When working towards design innovations for an interaction space, probing has the potential to deliver insights more focused on design than other context driven methods like the contextual inquiry. Apart from that, probing can support collaborative aspects and 
trigger participants to conduct probing activities through playful elements. The playful aspects of probing especially have lead to useful insights when conducting probing activities together with children in private contexts [3].

Within the car context, quantitative measures dominate studies conducted in the recent past. Cultural probes so far have not been applied. When approaching an interaction space like the rear seat, it is vital to understand the context and the experiences that evolve within the space. Due to their situational nature, these experiences are ideally captured in time and physical proximity. Probing as a method gives designers a tool to capture those experiences, reflect them and use them as a source of inspiration for future interaction designs. Other than in participatory design, probes are not artifacts, which directly lead to a new design solution. The user does not become a designer and does not make design decisions, which directly affect the interactive system. In our effort to design future in-car interfaces for that space, probing enables us to understand it generally before further detailed research questions can be developed addressing requirements for certain interactive systems. We argue that the usage of design methodology like probes will be well suited for addressing our research goals. Due to space limitations an extended discussion of the usefulness of probing as method cannot be conducted in this paper but is available in related literature (see for example [4], [7], [9]).

\section{Study Setup}

Since children are a main target group for the usage of the rear seat area, we invited 20 families (including single parents) for the study, explicitly asking for families whose kids mainly sit in the rear seat. While most probing studies aim at being completed by an individual user, we understand the car interior as shared space, thus we applied a collaborative probing approach having the family conducting the probing activities together. At least one member of the family was invited to an initial one-hour workshop where the method and the goal of the study were presented. Additionally the workshop was suitable to have a discussion about wishes towards the rear seat area. During the workshop, the probing package was handed over and explained. The participants kept the package for about four weeks conducting the activities as described in the next chapter. Every week, they received a reminder text message, after four weeks they sent the package back. After returning the packages, the participants were invited again to discuss the probes and the probing approach itself in a final workshop.

Since the car is a safety critical context, all participants were explicitly advised to follow traffic regulations and not to conduct any probing activities if this would reduce the traffic safety. No probing activity required the driver to get actively involved while driving. During the initial workshop, we highlighted the creative nature of cultural probing in order to avoid pressure to perform (e.g. "take the materials as inspiration, not as checklist"). At six initial workshops, probing packages were handed out to 20 participating families. 16 packages were returned after more than the four weeks; one family returned the package earlier. Three families either delivered no probes or returned the probing package too late to be invited for a final workshop. The 17 families that were included in the interpretation had in total 28 
children: 9 families with one child, 8 with 2 children, 1 with 3 and 1 family with 4 children. The mean age of the children was 6.7 years (SD: $4.32 ; n=28$ ); the youngest child was 1 , the oldest 16 years old.

\subsection{Probing Package}

Cultural probing includes the usage of a probing package which is intended to inspire the participants and give them tools to conduct the probes [7]. The probing package proposed in this work was developed to fit the automotive context. Activities that take more time and are distracting were designed to be conducted during breaks, for example in the spot where the car is parked. Probes which are actually taken in the car or within the context of a journey were quick to take and offered a scalable effort that allowed the participants to decide themselves how many resources they would like to invest.

The probing package included a roadbook, utilizing the metaphor of the diagrammatic book used in rally sports. The roadbook was a $21 \times 14.8 \mathrm{~cm}$ (DIN A5) booklet containing a double page for each probing activity (see details below). It additionally contained free pages for painting and other unstructured input and a page with the contact data of the study organizers. Apart from the roadbook, the probing package included materials needed to conduct the probing activities: pens, markers, glue, sticky notes, a disposable camera, postcards, stickers and a large sheet of paper for a collage (see figure 1).

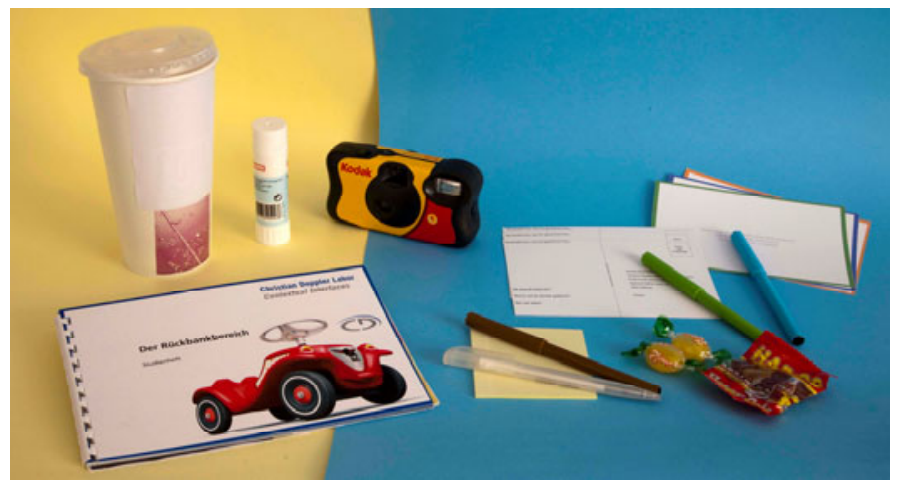

Fig. 1. Probing Package

All the items that were supposed to be taken into the car fit into a large cup as used in drive-in restaurants so that participants could easily store it in the car's cup holder. All other materials were stored in a poster carrier.

\subsection{Probing Activities}

The selection of probing tasks was developed by a concerned group of researchers having experience in the car domain and with probing. They discussed and gathered the most relevant aspects of the rear seat. In a second step, the researchers looked 
through the related literature and chose probing tasks, which were described to be working well, and which had an appropriate (low) workload for families conducting probing activities in the car. The variety of different probing activities was expected to be beneficial for the study goals - even if one probing approach was not used, the others could deliver valuable information. Each probing activity was linked to a different aspect of the rear seat and was therefore intended to deliver information on how HCI can address this aspect in future interaction designs. In order to motivate participants to take probes, each probing activity referred to a different situation, indicated by the headlines in this chapter.

\section{When the car is parked}

When using the car, different events and properties shape the perception of the rear seat area. An incident, for example, when kids hurt their hands because of automatic windows, will influence the parents' perception about this technology and potentially lead to a design intervention by the parents. It is useful to identify those modifications since they might solve problems or improve the rear seat, which makes them a valuable source of information on end user needs and wishes. In order to express these thoughts and stories, participants were equipped with a disposable camera and were explicitly encouraged also to use their own photo and video devices (e.g. a smartphone) if they felt more comfortable doing so.

We additionally gave colored stickers to the participants that were supposed to be stuck next to the interesting item before taking the picture, similar to a commenting tool. Some were pre-printed (super, bad, practical, impractical), some had space for comments to be written on.

\section{When we are at home}

A main goal of the probing study was to identify aspects of personalization in the rear seat area. Due to its properties, the back row of the car only allows a limited amount of personalization (e.g. electricity, limited storage...). We argue that, in everyday life, participants use spaces that allow a higher degree of modification and personalization than the car. A highly personalized space is, for example, the home. It is thus hypothesized that an insight on technologies, which improve other spaces, will allow the deduction of wishes for the rear seat area.

Thus participants were asked which technology from their everyday life (e.g. the household) they would like to include in the rear seat area of their car. The task was to take this technology, integrate it in the rear seat as good as possible and document this with the single-use camera. For technology, which was too heavy, too big or mounted permanently (e.g. refrigerator), the participants were asked to simply take a picture of it in its usual position.

\section{Before we leave}

In preparation for longer journeys, certain decisions have to be made and planning has to be conducted, especially when travelling with children.

Within the probing approach, the participants were given the opportunity to create a "perfect" rear seat for the trip. A 42 x $59.4 \mathrm{~cm}$ (DIN A2) sheet of photo carton was included in the probing package for that purpose. Participants were asked to create a 
collage showing the ideal rear seat area using magazines and other materials they had at home. This was done because personal magazines were intended to better reflect the participating household.

\section{When we are on the road}

Of special interest for researching the rear seat area were events that occurred during a trip or while being on the road. Therefore it was highly important to capture those events and the experiences made in the situation. For that purpose the probing package included self made postcards with pre-printed questions and space for creative input. The address field was already filled out and the postage prepaid.

Postcards were used because they have a decent size and grammage to write on in a car. Furthermore postcards have the right connotation when it is about sharing a short message from a trip. Each probing package contained three types of postcards, two copies each. The cards included questions for the destination on the backside, on the front side each card had a different topic encouraging participants to describe experiences or sketch them ("What do you like to do on the rear seat? What did you dislike on the rear seat today? What did you enjoy the most on the rear seat today?").

\section{When we get bored}

Boredom is one of the major problems when children are present in the rear seat area. The goal of this probe was to identify solutions for fighting boredom that are already used by the participants. This approach is based on the assumption that parents have highly qualitative concepts on fighting boredom, which are under constant evaluation and iteration in real life conditions. In the context of this study it was therefore necessary to capture those approaches in order to identify implications that support the design of technology that fights boredom. For that purpose, a double page in the road book was dedicated to capturing ideas regarding boredom and its avoidance; asking participants for what they do when sitting in the car gets boring.

\section{When something exciting happened.}

Probes can suffer from the downside that the appropriate probing material to record a certain situation is not available or left somewhere. Utilizing tools that are already possessed and carried by the participants could reduce this disadvantage. Within the study participants were given a phone number. They were asked to call that number whenever something interesting or exciting happened in the car to leave a message on the answering machine. This approach allowed participants to save a thought or an experience and share it with the researchers since mobile phones are available most of the time. Additionally the participants were also encouraged to send text or multimedia messages.

\section{Results}

Theoretical contributions on challenges of utilizing cultural probes within the design process have been presented by [9], among others. It has been pointed out that cultural probes are not analytical tools and their fragmentary nature requires particular 
attention. Addressing this issue, we followed an inductive and evolving process of data analysis, analogous to [12]. Taking into account the analysis of cultural probes in HCI presented by [4], we tried to include both the hermeneutic nature of the original probes and the data collection approach of more recent studies.

All probes were collected and digitalized, text passages on the collages were transcribed and pictures and drawings were described. The following data analysis included individual and collective sessions of analyzing the returned probes by five researchers with different backgrounds (communication science, computer science, interaction design). One researcher was responsible for collecting the probes and for digitalizing them. In a second step researchers with different backgrounds analyzed the probes commenting each probe with the topic it belonged to and the findings on this topic. All these comments were collected, grouped to the dimensions in the paper and interpreted. We additionally organized two half-day workshops with the participating researchers where the probes were discussed. In those workshops we focused on deducing design implications from the probes and on discussing ambivalent results. Each probe was analyzed regarding its explicit content and its implicit content (e.g. what was sketched, and what motivated the sketch, respectively). This phase took into account other probes of the particular family and attributes of this family (e.g. type of car, age of kids). The probes were tagged with results of this analysis, which was again collaboratively discussed to aggregate different perspectives. Based on those tags, a categorization structuring the results was made in order to identify areas of interest.

\subsection{Findings}

The following sections present a selection of insights gathered from the returned probes. Due to the high diversity of results and space limitations, we are not able to include all findings but intend on giving an overview on the nature of results.

\section{Aspects of diversion}

Activities conducted in the rear seat area played a central role in the results of the study. The main goal of those activities found in the probes was to entertain the children. This was often done to fight boredom, which again would cause troubles like kids fighting or complaining. Findings on boredom were frequent, since the probing material explicitly addressed boredom with the motivation that it will be one of the main application areas of future rear seat technology.

In order to fight boredom, participants used entertainment technology that they brought from home. Portable single user devices such as CD/ DVD Players and Nintendo Gameboys were mentioned. TVs were popular within the probes addressing wishes for future technology in the rear seat. The effect on other passengers when using technology in the car was always present in the probes. Devices like game boys and CD players aimed at one user at one time and therefore did not interfere with the interests of other persons in the car. To sum it up, music and video in general were reported to be a powerful tool against boredom, either through the car's HiFi system or through other devices such as musical instruments. 
Having music devices that can not be used without others listening (because they do not support headphones, for example) can cause annoyance for parents and be a reason for a fight between the children on the rear seat. One child stated that it is sometimes annoying for her mum when she listens to audio books and songs through her mother's CD player in the car.

Conflicts in that regard also existed due to a difference in age of the children. Audio books and songs played through the car HiFi system were annoying for kids in different ages because the content was not tailored for them.

Popular games played in the rear seat area involved counting a certain type of car (e.g. a cab) or cars with different characteristics (e.g. color, type of license plate). Also items in the landscape were used and included in games (e.g. "I spy with my little eye"). While those games would only work in a car, participants also played games that function outside of the car like thinking of a person and guessing who it is. Telling jokes was also mentioned as popular amusement as well as telling stories.

\section{Educational motivation}

Another identified type of activity was learning related, some parents used the available time for training or educating their kids. An activity aiming at this were quizzes, other kids did small math problems to be entertained but also to be kept mentally active. Others listened to CDs with some kind of educational content through their personal player or through the car's HiFi system. Books were also important to take, for entertainment but also for learning and studying purposes.

\section{Togetherness}

Activities for the whole family were often triggered by the parents. Some probes expressed that the time spent together in the car was not seen as "lost" but to be a family time where activities could be conducted together, creating a co-experience [1]: "We want to talk to the kids and sing with them. We don't want them to watch TV alone or listen to music with a headphone." In the car the whole family had the opportunity to talk, play and do things that may not be possible at home due to a busy schedule of each family member. For that purpose one family suggested a rotatable front chair making it possible to play games together, or simply look into each other's faces laughing and chatting.

Social and family life also influenced the choice for entertainment technology used in the rear seat. One family stated that they bought a portable DVD player for longer journeys because they did not want a built in device. That was for two reasons: The parents wanted to use the device for themselves outside of the car and as well as not wanting the kids to use the player when all three were sitting on the rear seat. Having a portable device therefore allowed the parents to use it more flexible and to better control its usage without having to argue with their kids about using the device. They just left it at home.

Rules and activities in the car also depended on the family member who was driving and who owned the car: "Sometimes we go with grandma and grandpa, but then we can not take anything with us and not make anything dirty, because grandma will get angry with us." 


\section{Food as activity}

A topic that occurred in the probes as popular activity in the rear seat was eating and drinking. Of the 14 collages that were returned, food or drinks were mentioned 11 times. Food items were used to satisfy hunger (e.g., bread, sausages, fruits) or just to snack (e.g., popcorn, ice cream, chocolate, chewing gum). Drink items included both cold (e.g., iced tea, water, juices) and hot drinks (e.g. coffee, to help fight sleepiness of the driver). Probes also reported about a mess produced by food in the rear seat. Not only food and drinks themselves were mentioned but probes also included appliances to cool (e.g., refrigerator), warm (e.g., microwave oven), make (e.g., coffee machine, mixer), or store food (e.g., functional cup holder). Food in the car also had the connotation of being entertaining often mentioned in combination with other activities against boredom.

\section{Physical space}

Storage is a central topic for adults travelling with kids in the rear seat of their car. Although cars usually offer high amount of compartments, the existing solutions do not appear to be suitable for families with young children. Cleanness in the rear seat was important for parents, aesthetic aspects were only mentioned by one family. For the participants functionality ruled once kids inhabited the rear seat space.

The main downside of current rear seats is missing accessibility. Fortunately, all participants used child seats, but apart from being beneficial for safety purposes, child seats also severely limit the movement of the children. For this purpose, most compartments and other storage locations in the rear seat area are not accessible for children. Most study participants solved that problem by installing seat hangers that are hung down on the back of both front row seats. The pockets of those are high enough and provide plenty of space for toys, books, pencils and something to drink. Accessibility is a major concern for adults because if kids do not have the possibility to grasp things they want, nobody is available to hand it to them.

Space in general is very limited in the rear seat. Families with only one kid used the other side of the seat for storage. If two child seats were necessary, only the narrow space between the two seats was available. Additionally, the floor is a useless space while driving. Children in their seats were neither able to put their feet on the floor nor could they pick up items which were accidently dropped. One parent stated: "If something falls on the floor, the children will scream until it is picked up again." Parents disliked the car floors because they were hard to clean, especially from liquid substances like ice cream and kids complained that they were not allowed to have ice cream in the car.

The collected collages showed the importance of comfort for participants. All returned collages included items to increase comfort. Among others items like blankets, mobile and integrated neck supports, and massage chairs were mentioned.

\section{Perception of Safety}

One major issue for the rear seat area was the safety of children. In the returned pictures safety belts were often illustrated. Child seats are a standard installation in the cars of the study participants and the most common adaption of the cars. Another object used for that purpose were baby monitors, one family stated that they wanted 
the baby monitor because their kids always fall asleep shortly before reaching the destination. Obviously they wanted to let their children sleep in the car but still be aware of what was going on in the car. On a collage the baby monitor was enhanced by a connection to a mobile phone.

\section{Mobile Computing}

Laptops with internet access were a stated wish for technology being available in the rear seat, as well as game consoles and television sets. Computers integrated in the car were seen as desirable (no USB dongle required to surf the web) but not affordable. Mobile phones were standard equipment in the rear seat, mainly for older kids. The internet was requested for sending emails and getting information about the route, mainly to find hotels or events going on in the surroundings. For all electronic devices participants requested power outlets within the reach of the rear seat area, the back of the first row seats was a popular spot to install those devices.

\subsection{Summary}

The presented results have shown the importance of six areas, derived from the probing study. (1) Fighting boredom through entertainment is one of the most important issues for both parents and children. Strategies used range from using modern technology (e.g. portable video, audio and gaming devices), to traditional toys, to social games without any technology usage. (2) Traveling in the car can be considered a family activity, that is often used consciously for various family related activities (e.g. discussion) and learning. (3) Especially on long trips comfort and wellbeing (e.g. eating, drinking, sleeping) are of high importance when driving with kids. Although this seems obvious, it has to be considered when introducing technology to the car. (4) The desire for space, storage and cleanness must not be underestimated. (5) Regarding safety and control, a balance between comfort and protection is to be found. Adults want to be aware what is going on the rear seat. (6) Computers and mobile phones are mainly used for communication and to stay connected to peer ties. Therefore, power supplies and persistent radio connection is required.

Some of our results might not be relevant to HCI in first place. Nevertheless, we believe that in a space like the rear seat area, different findings will not show their value until they are seen through the lens of a specific design problem. Food and drinks, for example, call for technology that sustains spills and stains. Seeing it in a wider perspective all available or not available artifacts have implications on the primary driving tasks and influence safety (for example: distraction through noise). Identifying those implications was a major goal of our study.

Overall the probing material inspired participants to creatively approach the rear seat areas in their cars. Feedback given by the participants showed that the probing study changed the way they saw their rear seat area. One participant left a handwritten note for the researchers saying: “(...) it was a lot of fun. Additionally, my husband finally put something for the kids into the car (e.g. reading light, drawer...)" The richness of the received probing data made it very valuable for this study. The method was explicitly carried out situational, all the material was produced within the participants natural surroundings and in close timely connection with an ongoing trip in the car, in the car and during trips (like the postcards). 


\section{Lessons Learned for the Design of Interactive Technology}

By gaining an understanding of the rear seat area, the following implications for the design of rear seat technology were collected. This collection took place after the accumulation of the results, again with all researchers participating in the process. In order to link the findings to the results, the relevant result chapters are mentioned in (emphasized) font.

\section{Gaming}

Playing games is already popular in the rear seat (aspects of diversion). However, future interactive technology will definitely bring games into rear seat devices. The games played in the rear seat area currently, give highly relevant input for the design of future rear seat games. All of them were multiplayer games, meaning that multiple kids on the rear seat played the game or that additionally one or both adults in the first row would join the game. Apart from a card game, all of the games mentioned in the probes did not involve any material to play the games but required imagination. All games were significantly influenced by the context they were played in.

The games did not require physical movement apart from turning your head and upper body (physical space). Since the infant carriers used restrict movement, the games were using fantasy, observation and memory as main tools. Most games were open ended with the possibility to adapt the length of the gameplay according to the available time. Games that were played had either short round by round interactions between the players or could be interrupted without ruining the gameplay. Most games also used the fact that the players were moving and that the physical context was dynamic (aspects of diversion). Those games would not be enjoyable at home in a room where, for example, the number of items with a single color is stable. Integrating aspects of education into the games is a promising approach, especially when it is aimed at topics related to the current trip (educational motivation). We strongly argue for including those aspects into future rear seat gaming technology since the context of play differs severely from other contexts like the home.

\section{Multiple users vs. single use}

Technology in the rear seat has to take both single and multiple user situations into account (togetherness). Therefore, several aspects of interactive systems have to be considered. Sound has to be used consciously in cars, bearing different interests and tastes of passengers in mind. Interestingly, some participants saw it as an annoyance that they had to listen to others music whilst some parents enjoyed listening to music together giving them the possibility to sing the songs as a family. "We dock our MP3 Player so that mum and dad can also listen to our music - Michael Jackson is awesome!" Technology therefore has to be flexible when being used as either single or multiple user technology.

Additionally, all kids need to have the same access to the interactive technology to avoid fights, as depicted in the painting presented in figure 2 , which includes three of each kind: iPods, headphones, reading lights, fans, portable gaming devices. As one parent stated after the kids got in a fight over something in the rear seat: "I think that technology in the rear seat area is only useful when all kids have the same items." 


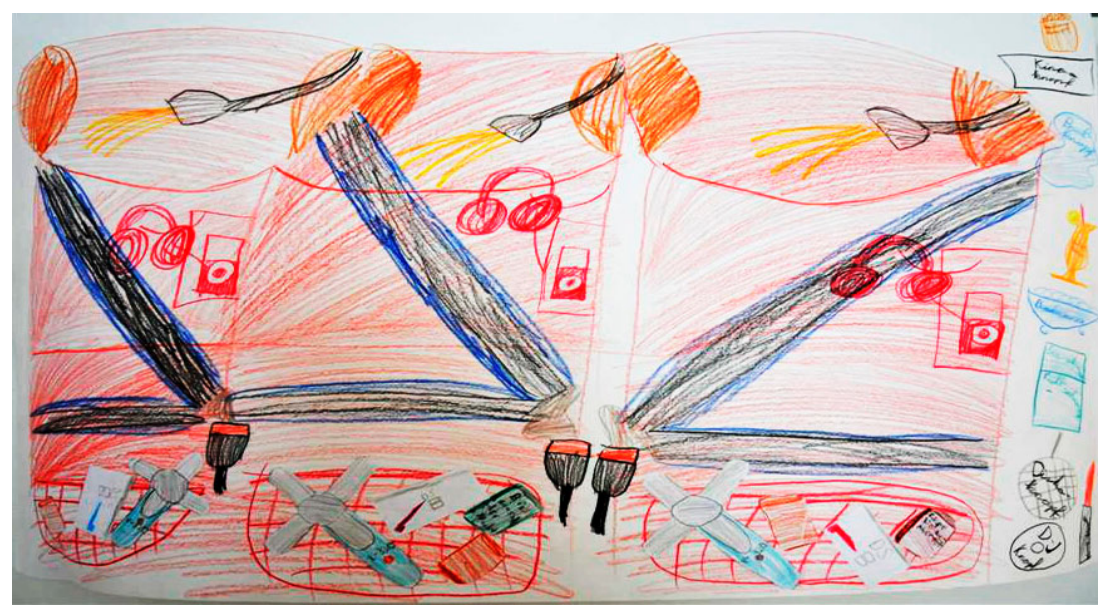

Fig. 2. Proposed rear seat layout with three identical seats

\section{Functionality}

When referring to devices they already had in the car (e.g. navigation system), participants expressed the wish to include child relevant functionality (aspects of diversion, educational motivation). Some children on the rear seat enjoyed playing with the portable navigation system when the driver did not need it and would have enjoyed functionality tailored to them (e.g. kids map, more pictures). Another functionality kids wanted was "a computer, which always tells us where we are, so we can mark where we have been and how we liked it there." What was identified as one major improvement area for in-car technology in general was that kids wanted to participate in using technology that is used by the adults. Integrating functionality for children will give them the possibility to participate.

Children also showed that they would like to take part in controlling the car. One kid even requested “(...) a horn and a speedometer, because sometimes dad goes too fast, I think, and then I can let him know. And I often see much better, if another car is doing something wrong - then I can honk." Rear seat technology should not only aim at entertaining children independently from the surrounding car and context of use. As kids see themselves as part of a joined travel activity they want to contribute to and support their parents' tasks (togetherness). Therefore, future interactive technology should allow the kids to take part in their parents' activity (e.g. driving, navigating) in the fashion of a co-driver.

\section{Interaction spaces}

Following the analysis of the probes, the rear seat can be divided into two spaces (physical space). The larger space is the dead space (1), which is out of reach and sight of children. Most of the floor and the lower part of the doors is dead space and so far only used for storage. Technology can be integrated in the dead space, but no physical interaction can take place. The active space (2) is the area on the backside of the front 
row seats, between the child seats, the seat itself and bellow the window. This area is currently used to store items for children giving them the possibility to interact with them. Integrating technology into this space may interfere with its current usage but will allow all kinds of interaction (mobile computing).

The seat area also has a strong connotation as personal space: "The best thing about the seat area is, that mum and dad are not there. (...) Therefore it is like a children's room, which is never entered by the adults." Most kids have their assigned place, where their child seat is mounted but also other personal items are arranged according to their wishes and needs. This creation of a bond to the certain place needs to be taken into consideration when introducing technology in the seat.

\section{Comfort and durability}

The high importance of food and drink in the seat in combination with a moving environment requires seat technology to sustain dirt created by groceries (food as activity). As comfort was considered highly important, integrated interactive systems must not lower the comfort of riding the car.

\section{Parental supervision}

Parents expressed the strong wish to be aware of what was going on in the rear seat while driving (e.g. with an additional mirror) but also while the car is parked (e.g. using a baby monitor). During driving, interactive technology has to keep parents in control when and how the technology is used (perception of safety). Adults have to be able to limit the usage of the devices or set them to certain modes like switching from single user mode to an application the whole family can enjoy. The portability of certain parts of the technology can additionally support the parents in banning the usage of the device. This part can be left at home and children should understand that this device cannot be used when the part is not available.

Additionally, technology should support the parents in observing the car while it is parked. Although it can be a safety thread, leaving the child in the car can also be beneficial as long as the parent knows what is going on, preferably through audio and video. Usage scenarios mentioned by participants were for example when the car is parked at home and kids are sleeping or when children want to finish a book chapter and come into the house later.

\subsection{Summary}

The findings give insights on what aspects of the rear seat have to be taken into account when designing technology for that space. Although not all returned probes lead to novel insights, the richness of the probing data has the potential to inspire designers experts with different backgrounds (e.g. psychologists). Even if not all findings can be considered being innovative, our work contributes to the design of rear seat technology by summing up and structuring aspects relevant for interactions in that space. To make the impact of the findings clearer the following chapter will show an example design idea derived from the results. 


\section{Design Concept: Riddle Ride}

In order to illustrate the usefulness of the probing approach and its' results, we developed the concept for a novel rear seat entertainment system called RiddleRide (RR). The design decisions in the proposed system are related to design inspirations (which are emphasized) from the probing study. The focus of the design concept is not on technical feasibility, but to make a first step in an innovation centered design process of a new interactive rear seat system.

RiddleRide is a multiplayer quiz gaming application. Its main purpose is to entertain and educate passengers (education) both children and adults in the car during a ride. $\mathrm{RR}$ is round-based, automatically detecting the number of players and giving questions via speech through the built in sound system. Each question is read aloud, letting all passengers participate and allowing kids who cannot read yet to join the game (family activity). No additional visual displays need to be installed in spots that are already taken by other installations such as seat hangers (interaction spaces). Since RR is round based, it gives all passengers time to answer their questions and makes it easy to stop the game at anytime and to start it again (interruption of games). After each player gives an answer, RR informs about the correct response and of the current scores. Since all players get the same question, RR aims at creating a coexperience [1] and makes playing the game a family activity.

Answers are displayed on mobile devices that are already in the family's possession, such as Nintento DS, iPhone, Playstation Portable, Android Phones, tablets or any kind of device that supports a wireless connection. This reduces investment costs, allows the children to use interaction devices and modalities they are already familiar with and reduces potential fights over equipment by the children, since everyone can use their own belonging (multi vs. single user). Additionally, these mobile devices are within reach, easy to store away (limited space), and sustain dirt and liquid to an extend, which is necessary for the child (durability). The mobile devices can also be used with headphones reducing the distraction for the other passengers, when playing RR as a single player.

RiddleRide is intended to entertain both children and grown-ups by adapting the answers given to the questions. To make the game interesting and challenging for different age and skill groups, RR automatically changes the level of difficulty for each player based on their performance keeping the tasks within the "zone of proximal development [18]". While quiz games usually control difficulty through the question, RR uses the answers for that purpose, since the question is the same for all players (family activity). Tools to in- or decrease the difficulty vary from the number if answer possibilities, number of potentially right answers and graphic representation of answers (see figure 3).

An important aspect is the educational value of the game, therefore all quiz questions have an educational purpose. RR is context aware, meaning that questions asked are related to the surrounding in which the vehicle is currently moving and to the destination of the trip (context sensitive gaming). RR is compatible with all kinds of trip durations, since it can be stopped at anytime delivering a score after each question. The fact that RR uses audio output for the questions, it reduces the influence of context factors such as bright sunlight. The volume of RR adapts automatically to the ambient noise in the car cabin (context sensitivity). Through the connection to car 
telematic systems, RiddleRide will be able to detect situations were distraction has to be minimized (e.g. dangerous road conditions). In those situations the game will either be disabled or playing the game will only be possible with headphones.

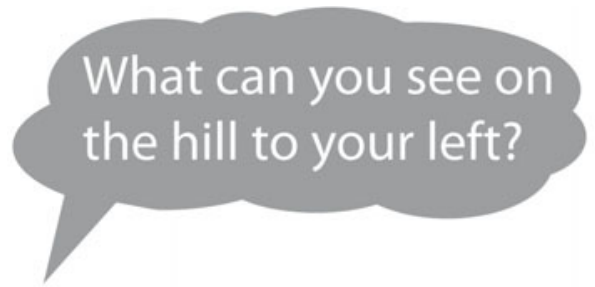

Question from RiddleRide

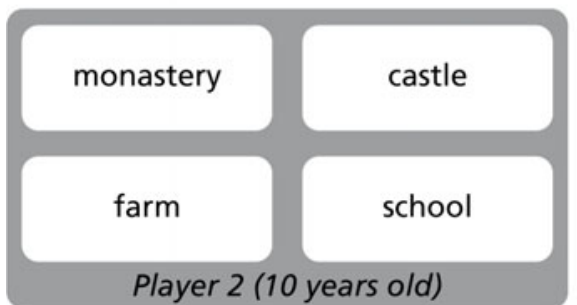

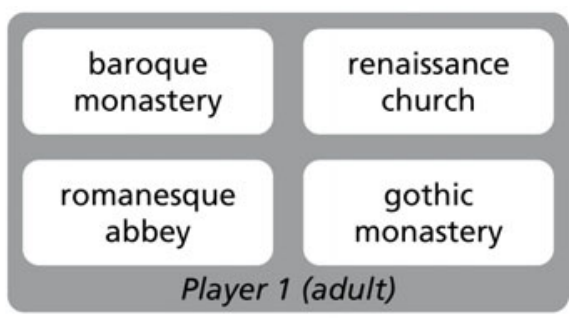

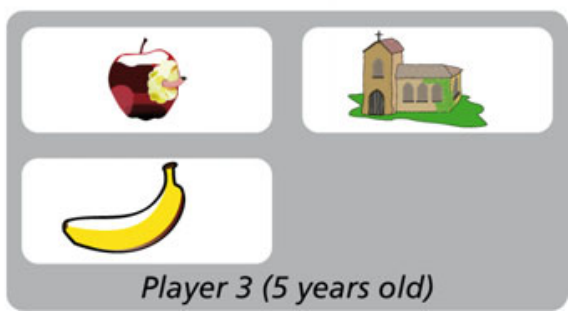

Fig. 3. Question from RR, asking for the monastery that appears on the left side of the car on a hill. The three players get different answers presented, varying in number, visual style and similarity to adjust the difficulty.

When adults are present and not driving they also get the possibility to administer the game. They can choose topics, change game settings or simply disable the game when the children are not allowed to play (parental supervision) among other things. The driver is also included in RR. Since distraction from the driving task has to be reduced to a minimum, the driver acts as joker, who can support the other passengers when they need help. The role as joker allows the driver to join the game since it is neither stressful nor time critical. Additionally, the driver can control, when to answer and then to deny an answer if the driving workload is too high for additional tasks. Including the driver makes RiddleRide a real family activity.

By giving this design example, the applicability of the probing study results as reflected in design decisions are shown. As a next step we will create prototypes of RiddleRide to study the game in the real context of use. We are aware of potential safety threats caused by technology in the vehicle, which is why RiddleRide will undergo a rigorous evaluation process during its development.

\section{Conclusions}

As its main contribution, this work informs the user experience centered development of future interactive technology in the rear seat. Even if not all findings can be considered being innovative, our work contributes to the design of rear seat technology by summing up and structuring aspects, which relevant for interactions in that space. 
We were able to gather information about the constitution of user experience in the rear seat. With this information, designers in the automotive context can make conscious design decisions being aware of the effect their decisions will have on the UX in the car. The conducted study provides information on functionality, installation and interaction modalities of future interactive rear seat systems. Results from the probes show the importance of focusing on experiences rather than on what is technically possible in the rear seat. Being unaware of the experience laden processes when designing interactive systems, will lead to negative experiences, rejection of the system and in the worst case to severe safety threats for all passengers.

Acknowledgments. The financial support by the Federal Ministry of Economy, Family and Youth, the National Foundation for Research, Technology and Development and AUDIO MOBIL Elektronik GmbH is gratefully acknowledged (Christian Doppler Laboratory for "Contextual Interfaces").

\section{References}

1. Batarbee, K.: Co-Experience. Ph.D. thesis. University of Art and Design Helsinki (2004)

2. Berkovich, M.: Perspective probe: many parts add up to a whole perspective. In: Proceedings of the 27th International Conference Extended Abstracts on Human Factors in Computing Systems, CHI 2009, pp. 2945-2954. ACM, New York (2009)

3. Bernhaupt, R., Wilfinger, D., Weiss, A., Tscheligi, M.: An ethnographic study on recommendations in the living room: Implications for the design of itv recommender systems. In: Tscheligi, M., Obrist, M., Lugmayr, A. (eds.) EuroITV 2008. LNCS, vol. 5066, pp. 92-101. Springer, Heidelberg (2008)

4. Boehner, K., Vertesi, J., Sengers, P., Dourish, P.: How HCI interprets the probes. In: Proceedings of the SIGCHI Conference on Human Factors in Computing Systems, CHI 2007, pp. 1077-1086. ACM, New York (2007)

5. Buechley, L., Rosner, D.K., Paulos, E., Williams, A.: Diy for chi: methods, communities, and values of reuse and customization. In: Proceedings of the 27th International Conference Extended Abstracts on Human Factors in Computing Systems, CHI 2009, pp. 4823-4826. ACM, New York (2009)

6. Forlizzi, J., Barley, W.C., Seder, T.: Where should i turn: moving from individual to collaborative navigation strategies to inform the interaction design of future navigation systems. In: CHI 2010: Proceedings of the 28th International Conference on Human Factors in Computing Systems, pp. 1261-1270. ACM, New York (2010)

7. Gaver, B., Dunne, T., Pacenti, E.: Design: Cultural probes. Interactions 6(1), 21-29 (1999)

8. Geiser, G.: Man Machine Interaction in Vehicles. ATZ 87, 74-77 (1985)

9. Graham, C., Rouncefield, M., Gibbs, M., Vetere, F., Cheverst, K.: How probes work. In: Proceedings of the 19th Australasian Conference on Computer-Human Interaction: Entertaining User Interfaces, OZCHI 2007, pp. 29-37. ACM, New York (2007)

10. Kim, H., Monk, A.: Emotions experienced by families living at a distance. In: Proceedings of the 28th of the International Conference Extended Abstracts on Human Factors in Computing Systems, CHI EA 2010, pp. 2923-2926. ACM, New York (2010)

11. Koskinen, I.: Hacking a car: Re-embodying the design classroom. In: Nordic Design Research Conference Nordes 2009 (2009), http: / / nordes . org 
12. Leonardi, C., Mennecozzi, C., Not, E., Pianesi, F., Zancanaro, M., Gennai, F., Cristoforetti, A.: Knocking on elders' door: investigating the functional and emotional geography of their domestic space. In: Proceedings of the 27th International Conference on Human Factors in Computing Systems, CHI 2009, pp. 1703-1712. ACM, New York (2009)

13. Mahr, A., Pentcheva, M., Müller, C.: Towards system-mediated car passenger communication. In: Proceedings of the 1st International Conference on Automotive User Interfaces and Interactive Vehicular Applications, pp. 79-80. ACM, New York (2009)

14. NHTS: National household travel survey, http: / / nhts . ornl gov/

15. Petrelli, D., van den Hoven, E., Whittaker, S.: Making history: intentional capture of future memories. In: Proceedings of the 27th International Conference on Human Factors in Computing Systems, CHI 2009. ACM, New York (2009)

16. Schmidt, A., Dey, A.K., Kun, A.L., Spiessl, W.: Automotive user interfaces: human computer interaction in the car. In: Proceedings of the 28th of the International Conference Extended Abstracts on Human Factors in Computing Systems, CHI EA 2010, pp. 31773180. ACM, New York (2010)

17. Vyas, D., Eliens, A., van de Watering, M.R., van der Veer, G.C.: Organizational probes: exploring playful interactions in work environment. In: Proceedings of the 15th European Conference on Cognitive Ergonomics: the Ergonomics of Cool Interaction, ECCE 2008, pp. 35:1-35:4. ACM, New York (2008)

18. Vygotsky, L.: Mind in Society. The Development of Higher Psychological Processes. Harvard University Press, Cambridge (1978) 